\title{
High cardiometabolic risk in healthy Chilean adolescents: associations with anthropometric, biological and lifestyle factors
}

\author{
Raquel Burrows ${ }^{1, *}$, Paulina Correa-Burrows ${ }^{1}$, Marcela Reyes $^{1}$, Estela Blanco ${ }^{2}$, \\ Cecilia Albala ${ }^{1}$ and Sheila Gahagan ${ }^{2}$ \\ ${ }^{1}$ Institute of Nutrition and Food Technology, University of Chile, Avda. El Líbano 5524, Macul 7840390, Santiago \\ de Chile, Chile: ${ }^{2}$ Division of Child Development and Community Health, University of California, San Diego, La Jolla, \\ CA, USA
}

Submitted 24 November 2014: Final revision received 31 March 2015: Accepted 14 April 2015: First published online 20 May 2015

\begin{abstract}
Objective: To analyse the prevalence of cardiovascular risk factors in healthy adolescents of low to middle socio-economic status and to study the influence of anthropometric, biological and lifestyle factors on the risk of metabolic syndrome (MetS).

Design: Cross-sectional study. BMI, waist circumference, blood pressure, fat and lean mass (by dual-energy X-ray absorptiometry), TAG, HDL-cholesterol, glucose, insulin, homeostatic model assessment-insulin resistance index (HOMA-IR), food intake and physical activity were measured. Cardiovascular risk factors were defined using the International Diabetes Federation criteria and insulin resistance using HOMA-IR $\geq 2 \cdot 6$. Bivariate and multivariate regressions examined the associations between MetS and anthropometric, biological and lifestyle factors.

Setting: Observational cohort study including Chilean adolescents, who were part of a follow-up study beginning in infancy.

Subjects: Adolescents aged 16-17 years ( $n$ 667).

Results: In the sample, $16.2 \%$ had obesity and $9.5 \%$ had MetS. Low HDLcholesterol (69.9\%), abdominal obesity (33.3\%) and fasting hyperglycaemia $(8.7 \%)$ were the most prevalent cardiovascular risk factors. In males, obesity $(\mathrm{OR}=3.7 ; 95 \% \mathrm{CI} 1 \cdot 2,10 \cdot 8)$, insulin resistance ( $\mathrm{OR}=3.0 ; 95 \% \mathrm{CI} 1 \cdot 1,8.2)$, physical inactivity $(\mathrm{OR}=2 \cdot 9 ; 95 \% \mathrm{CI} 1 \cdot 1,7 \cdot 7)$ and sarcopenia $(\mathrm{OR}=21 \cdot 2 ; 95 \% \mathrm{CI}$ $4 \cdot 2,107 \cdot 5)$ significantly increased the risk of MetS. In females, insulin resistance $(\mathrm{OR}=4.9 ; 95 \% \mathrm{CI} 1.9,12.6)$ and sarcopenia $(\mathrm{OR}=3.6 ; 95 \% \mathrm{CI} 1.1,11.9)$ were significantly associated with MetS.

Conclusions: High prevalences of obesity, abdominal obesity, dyslipidaemia, fasting hyperglycaemia and MetS were found in healthy adolescents. In both sexes, sarcopenia and insulin resistance were important risk factors of MetS. Promotion of active lifestyles at the school level and regulation of the sale of energy-dense foods are needed.
\end{abstract}

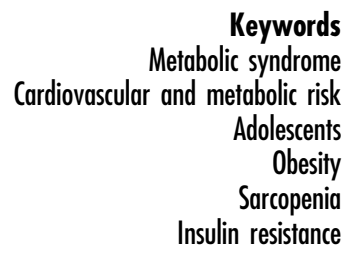

The growing prevalence of overweight and obesity has led to higher rates of type 2 diabetes and CVD, both of which may be preceded by the metabolic syndrome (MetS) during childhood and adolescence ${ }^{(1,2)}$. The MetS is a clustering of cardiometabolic disorders, including abdominal obesity, fasting hyperglycaemia, dyslipidaemia and hypertension, and it allows early identification of individuals with future risk of type 2 diabetes and cardiovascular disorders ${ }^{(3,4)}$. Cardiovascular and metabolic diseases currently account for the greatest loss of healthy life years, not to mention the economic burden, which is expected to keep growing due to higher life expectancy rates ${ }^{(5,6)}$. In children and adolescents, MetS is associated with inflammation, insulin resistance (IR), obesity, and a Western diet and sedentary lifestyle $^{(7-10)}$. IR is the most common metabolic alteration related to obesity and, similarly, is an important link between obesity and MetS, type 2 diabetes and cardiovascular complications ${ }^{(7,9)}$. Moreover, during childhood and adolescence, a negative association between muscular fitness and cardiometabolic risk has been found ${ }^{(11)}$.

The Organization for Economic Co-operation and Development and the WHO have recognized unhealthy diets and physical inactivity as strong early determinants of obesity and non-communicable chronic diseases in 
adulthood $^{(12)}$. In the last three decades, Chile underwent a remarkable nutritional transition, with increasing Western dietary patterns and inactive lifestyles resulting in high prevalences of obesity, type 2 diabetes and CVD, particularly in low socio-economic levels ${ }^{(13-15)}$. From 1986 to 1998, the odds of obesity increased sixfold in boys and fourfold in girls aged $6-16$ years $^{(16)}$. Likewise, high rates of IR (53\%) and MetS (30\%) have been documented among obese Chilean children and adolescents aged 4-16 years ${ }^{(17,18)}$. A more recent study in children and adolescents attending public schools showed prevalence rates of obesity, MetS and IR of $16 \cdot 1 \%, 7.3 \%$ and $25.9 \%$, respectively ${ }^{(19)}$. Furthermore, in the 2011 Physical Activity System for the Assessment of Educational Quality (SIMCE_EF), a national standardized test administered to all 8th grade students, an obesity prevalence of $16 \%$ was confirmed, whereas $93 \%$ and $78 \%$ of assessed students had impaired muscle functioning and low aerobic capacity, respectively ${ }^{(20)}$.

The aim of the present study was to analyse the prevalence of cardiovascular risk factors and the influence of anthropometric, biological and lifestyle factors on odds for MetS in a cohort of healthy Chilean adolescents, who were part of randomized controlled trial of Fe to prevent Fe deficiency in infancy and a longitudinal follow-up study.

\section{Methods}

\section{Study design and population}

We studied 667 adolescents aged 16-17 years of low to middle socio-economic status (SES), living in urban Santiago, who were part of a follow-up study beginning in infancy. The infants, recruited at 4 months, were healthy, full-term singleton infants weighing $3 \mathrm{~kg}$ or more at birth. At 6 months, those who were not Fe deficient were randomized to receive Fe supplementation or usual nutrition from 6 to 12 months. They were assessed for developmental outcomes in infancy and at 5,10 and 16 years. At 16 years, they were also assessed for obesity risk and the presence of cardiovascular risk factors ${ }^{(21)}$. The study was approved by the institutional review boards of the University of Michigan, the Institute of Nutrition and Food Technology (University of Chile), and the University of California, San Diego. Participants and their primary caregiver provided informed and written consent, which was obtained according to the norms for Human Experimentation, Code of Ethics of the World Medical Association (Declaration of Helsinki, 1995).

\section{Measurements}

\section{Anthropometry and body composition}

A research physician used standardized procedures to measure the adolescent's height to the nearest $0.1 \mathrm{~cm}$ using a Holtain stadiometer and weight to the nearest $0 \cdot 1 \mathrm{~kg}$ using a Seca scale. BMI $\left(\mathrm{kg} / \mathrm{m}^{2}\right)$ was calculated and obesity status was calculated according to WHO references. Waist circumference (WC) was measured with non-elastic flexible tape at the high point of the iliac crest around the abdomen and recorded to $0.1 \mathrm{~cm}$. Measurements were taken twice, with a third measurement if the difference between the first two exceeded $0.3 \mathrm{~kg}$ for weight, $0.5 \mathrm{~cm}$ for height and $1.0 \mathrm{~cm}$ for waist. Dual-energy X-ray absorptiometry was used to measure fat mass (\%) and fat-free mass (\%). Fat-free mass index was estimated according to Wells and Fewtrell ${ }^{(22)}$. Fat-free mass index values were expressed as a percentage; values $\leq 25$ th percentile in our sample, adjusted for sex, were defined as relative sarcopenia. In the remainder of the paper we use the term 'sarcopenia' to refer to relative sarcopenia.

\section{Additional cardiovascular risk markers}

After $15 \mathrm{~min}$ at rest and before the other physical evaluations, systolic and diastolic blood pressures (SBP and DBP) were measured three times on the non-dominant arm using a standard mercury sphygmomanometer; the average value was used for analyses. Fasting serum total glucose, cholesterol, TAG, HDL-cholesterol (HDL-C), insulin, adiponectin and high-sensitivity C-reactive protein (hs-CRP) levels were performed after a $12 \mathrm{~h}$ overnight fast. RIA (Diagnostic Products Corporation, Los Angeles, CA, USA) was used for insulin and adiponectin determinations. hs-CRP was measured with a sensitive latex-based immunoassay. Glucose was measured with an enzymatic colorimetric test (QCA S.A., Amposta, Spain) and cholesterol profile (HDL-C and TAG, mg/dl) were determined by dry analytical methodology (Vitros ${ }^{\circledR}$; Ortho Clinical Diagnostics Inc., Raritan, NJ, USA). Homeostatic model assessment-insulin resistance index (HOMA-IR) was calculated and a value of 2.6 was considered to indicate $\mathrm{IR}^{(23)}$. Values of hs-CRP $\geq 1.1 \mathrm{mg} / 1$ (75th percentile in our sample) were considered low-grade systemic (LGS) inflammation and values of adiponectin $\leq 7.9 \mu \mathrm{g} / \mathrm{ml}$ (25th percentile in our sample) were considered to be low.

\section{Definition of metabolic syndrome and cardiovascular risk factors}

In order to compare our results with findings from other national and international studies, MetS was diagnosed based on the 2007 International Diabetes Federation (IDF) consensus statement on the clinical definition of the MetS in the paediatric age range. These criteria include having central obesity plus two of the other four factors using the following definitions: (i) abdominal obesity (WC $\geq 80$ and $\geq 90 \mathrm{~cm}$ in females and males, respectively); (ii) high blood pressure (SBP $\geq 130 \mathrm{mmHg}, \quad \mathrm{DBP} \geq 85 \mathrm{mmHg}$ ); (iii) hypertriacylglycerolaemia (TAG $\geq 150 \mathrm{mg} / \mathrm{dl}$ ); (iv) low HDL-C ( $\leq 50$ and $\leq 40 \mathrm{mg} / \mathrm{dl}$ in female and male adolescents, respectively); and (v) fasting hyperglycaemia (total glucose $\geq 100 \mathrm{mg} / \mathrm{dl})^{(24)}$. The cardiovascular risk factors 
included each criterion of the IDF definition of MetS. The new MetS definition by the IDF and American Heart Association/National Heart, Lung, and Blood Institute (AHA/NHLBI) ${ }^{(25)}$ was used to assess potential differences in the prevalence of MetS.

\section{Food intake and physical activity}

Food intake and physical activity habits were measured using validated and standardized self-report questionnaires and scored from 0 to 10 , with higher scores denoting better quality of food intake or more physical $\operatorname{activity}^{(26,27)}$. The questionnaires were administered by a researcher during the half-day assessment. The quality of food intake was measured by the amounts of saturated fat, fibre, sugars and salt in the food items. We applied cut-offs from a national reference standard ${ }^{(26)}$ to classify the eating habits of participants into three groups: unhealthy (score $\leq 4 \cdot 30)$, intermediate (score $=4 \cdot 31-5 \cdot 99)$ and healthy (score $\geq 6 \cdot 00$ ). Physical activity was measured by the total amount of time devoted to sedentary activities, recreational games, active commuting, and weekly scheduled exercise either school or non-school organized. Participants with a score $\leq 3.00$ were classified as physically inactive, those with a score $\geq 6.00$ were physically active, and those in between were moderately active ${ }^{(26)}$.

\section{Statistical analysis}

Statistical analysis included Student's $t$ test and Wilcoxon's rank-sum test for comparison of mean or median values of anthropometric, cardiometabolic and lifestyle variables. The $\chi^{2}$ test was used for comparison of categorical variables. Given biological and lifestyle differences between male and female adolescents, we tested interactions between sex, anthropometric and biological factors on development of MetS by using two-way ANOVA. The interaction with sex was significant at $\alpha$ level of 0.05 (data not shown) and, therefore, we stratified the analysis. After performing unadjusted logistic regressions to test the associations between MetS and biological (LGS inflammation, low adiponectin and IR), anthropometric (obesity and relative sarcopenia) and lifestyle (physical inactivity and unhealthy food intake) variables, we used multiple logistic regressions to assess the relationship between the risk of MetS and the variables significantly associated with MetS. Three models were estimated. The first one included biological variables. In the second model, anthropometric variables were added. Finally, a fully adjusted model contained all mentioned covariates with the addition of lifestyle factors. Data were analysed using the statistical software package Stata for Windows version 12.0. A $P$ value of $<0.05$ denoted statistical significance.

Table 1 Anthropometric, cardiometabolic and lifestyle profile in healthy male and female adolescents aged 16-17 years from Santiago, Chile (n 667)

\begin{tabular}{|c|c|c|c|c|c|c|}
\hline & \multicolumn{2}{|c|}{ Males $(n$ 348) } & \multicolumn{2}{|c|}{ Females $(n$ 319) } & \multicolumn{2}{|c|}{ Overall sample ( $n$ 667) } \\
\hline & Mean or \% & SD or $95 \% \mathrm{Cl}$ & Mean or $\%$ & SD or $95 \% \mathrm{Cl}$ & Mean or \% & SD or $95 \% \mathrm{Cl}$ \\
\hline \multicolumn{7}{|c|}{ Continuous variables (mean and SD) } \\
\hline Age (years) & $16 \cdot 8$ & 0.2 & $16 \cdot 8^{*}$ & 0.3 & $16 \cdot 8$ & 0.3 \\
\hline BMI (Z-score) & 0.58 & 1.2 & $0.73^{*}$ & $1 \cdot 2$ & 0.65 & 1.2 \\
\hline WC $(\mathrm{cm})$ & $81 \cdot 3$ & $11 \cdot 1$ & 81.2 & 11.8 & $81 \cdot 2$ & 11.4 \\
\hline Total fat mass $(\%)$ & $22 \cdot 4$ & $8 \cdot 8$ & $36 \cdot 3^{\star \star \star}$ & 7.5 & $29 \cdot 0$ & $10 \cdot 5$ \\
\hline Total fat-free mass $(\%)$ & 74.5 & $9 \cdot 0$ & $59 \cdot 9^{\star \star \star}$ & $7 \cdot 5$ & $67 \cdot 6$ & $10 \cdot 8$ \\
\hline SBP $(\mathrm{mmHg})$ & $115 \cdot 4$ & $10 \cdot 4$ & $108 \cdot 8^{\star \star \star}$ & $9 \cdot 7$ & $112 \cdot 2$ & $10 \cdot 6$ \\
\hline DBP $(\mathrm{mmHg})$ & $70 \cdot 8$ & $7 \cdot 0$ & $67 \cdot 6^{* \star \star}$ & $6 \cdot 7$ & $69 \cdot 3$ & $7 \cdot 0$ \\
\hline Glucose $(\mathrm{mg} / \mathrm{dl})$ & 90.4 & $9 \cdot 6$ & $86 \cdot 5^{\star \star \star}$ & $9 \cdot 0$ & 88.5 & 9.5 \\
\hline Insulin $(\mu \mathrm{U} \mathrm{l} / \mathrm{ml})$ & $7 \cdot 8$ & $5 \cdot 7$ & 8.4 & $5 \cdot 3$ & $8 \cdot 1$ & 5.5 \\
\hline HOMA-IR & 1.8 & 1.4 & 1.8 & 1.2 & 1.8 & 1.3 \\
\hline TAG (mg/dl) & 88.4 & $52 \cdot 4$ & 88.2 & 47.6 & 88.3 & $50 \cdot 2$ \\
\hline HDL-C (mg/dl) & 38.0 & $10 \cdot 1$ & $42 \cdot 5^{\star \star \star}$ & $10 \cdot 7$ & $40 \cdot 1$ & $10 \cdot 6$ \\
\hline hs-CRP (mg/l) & 1.0 & 2.2 & 1.0 & 1.8 & 1.0 & 1.9 \\
\hline Adiponectin $(\mu \mathrm{g} / \mathrm{ml})$ & $10 \cdot 7$ & $5 \cdot 2$ & $13 \cdot 0^{\star \star *}$ & 5.6 & $11 \cdot 8$ & 5.5 \\
\hline Physical activity (score) & $5 \cdot 0$ & $2 \cdot 0$ & $3 \cdot 0^{* \star \star}$ & 1.0 & 4.0 & $2 \cdot 0$ \\
\hline Food intake (score) & $5 \cdot 2$ & 1.2 & $5 \cdot 3$ & 1.3 & $5 \cdot 2$ & $1 \cdot 2$ \\
\hline \multicolumn{7}{|c|}{ Categorical variables ( $\%$ and $95 \% \mathrm{Cl}$ ) } \\
\hline LGS inflammation & $20 \cdot 1$ & $15 \cdot 8,24 \cdot 3$ & $24 \cdot 1$ & $19 \cdot 4,29 \cdot 9$ & $22 \cdot 0$ & $18 \cdot 9,25 \cdot 2$ \\
\hline Low adiponectin & $24 \cdot 1$ & $19 \cdot 6,28 \cdot 6$ & $12 \cdot 2^{\star \star \star}$ & $8 \cdot 6,15 \cdot 8$ & $18 \cdot 4$ & $15 \cdot 5,21 \cdot 4$ \\
\hline Insulin resistance & $16 \cdot 0$ & $12 \cdot 1,19 \cdot 9$ & $16 \cdot 6$ & $12 \cdot 5,20 \cdot 7$ & $16 \cdot 5$ & $13 \cdot 6,19 \cdot 3$ \\
\hline Obesity & $15 \cdot 8$ & $11.9,19.6$ & $17 \cdot 0$ & $12 \cdot 8,21 \cdot 2$ & $16 \cdot 1$ & $13 \cdot 4,19 \cdot 0$ \\
\hline Sarcopenia & 24.9 & $20 \cdot 4,29 \cdot 5$ & $25 \cdot 4$ & $20 \cdot 6,30 \cdot 2$ & $25 \cdot 1$ & $21 \cdot 9,28 \cdot 4$ \\
\hline Physical inactivity & 24.4 & $19 \cdot 8,29 \cdot 0$ & $57 \cdot 9^{\star \star \star}$ & $52 \cdot 4,63 \cdot 3$ & $40 \cdot 8$ & $37 \cdot 0,44 \cdot 6$ \\
\hline Unhealthy food intake & $23 \cdot 2$ & $18 \cdot 8,27 \cdot 7$ & $24 \cdot 5$ & $19 \cdot 7,29 \cdot 2$ & $23 \cdot 8$ & $20 \cdot 6,27 \cdot 0$ \\
\hline
\end{tabular}

WC, waist circumference; SBP, systolic blood pressure; DBP, diastolic blood pressure; HOMA-IR; homeostatic model assessment-insulin resistance index; HDL-C, HDL-cholesterol; hs-CRP, high-sensitivity C-reactive protein; LGS, low-grade systemic.

LGS inflammation: hs-CRP $\geq 75$ th percentile (hs-CRP $\geq 1.1 \mathrm{mg} / \mathrm{l}$ ). Low adiponectin: adiponectin $\leq 25$ th percentile (adiponectin $\leq 7.9 \mu \mathrm{g} / \mathrm{ml}$ ). Insulin resistance: HOMA-IR $\geq 2$.6. Obesity: BMI Z-score $\geq 2$. Relative sarcopenia: $\%$ fat-free mass index $\leq 25$ th percentile. Physical inactivity: physical activity score $\leq 3$. Unhealthy food intake: food intake score $\leq 3.3$.

Significant difference between males and females (Student's $t$ test, Wilcoxon rank-sum test or $\chi^{2}$ test): ${ }^{*} P<0.05$, ${ }^{\star * \star} P<0.001$.

†Expressed as median and interquartile range. 


\section{Results}

The participants were $16.8(\mathrm{sD} 0.3$ ) years old, and $52.2 \%$ male. The prevalence of obesity was $16 \cdot 2 \%$ (95\% CI $13 \cdot 4$, $18.9 \%)$. At least one cardiovascular risk factor was present in $79 \%$ of the participants and $9.5 \%$ (95\% CI 7.2, $11.7 \%)$ met criteria for the MetS. When the MetS was diagnosed by using the new IDF and AHA/NHBLI definition, the prevalence increased to $9 \cdot 8 \%$ (95\% CI 7.5, 12.0\%).

Table 1 shows the anthropometric, cardiometabolic and lifestyle characteristics of adolescents in the sample by sex. Males had significantly higher mean values of blood pressure (SBP and DBP), glycaemia and physical activity score, and lower levels of adiponectin and HDL-C, compared with females. Prevalence of low adiponectin was significantly higher in males, while physical inactivity was significantly higher in females (all $P<0 \cdot 001$ ).

In the overall sample, low HDL-C (69.9\%; $95 \%$ CI 66.4, $73.4 \%)$ and abdominal obesity (33.3\%; $95 \%$ CI 29.7 , $36.9 \%)$ were the most prevalent cardiovascular risk factors (Fig. 1). Fasting hyperglycaemia prevalence was $8.7 \%$ (95\% CI $6.5,10 \cdot 8 \%$ ). After controlling sex, males had a higher prevalence of elevated blood pressure than females $(P<0.001)$. Females had a higher prevalence of abdominal obesity $(P<0.001)$ and low HDL-C $(P<0.01)$ than males.

Tables 2 and 3 present the estimated associations between biological, anthropometric and lifestyle factors

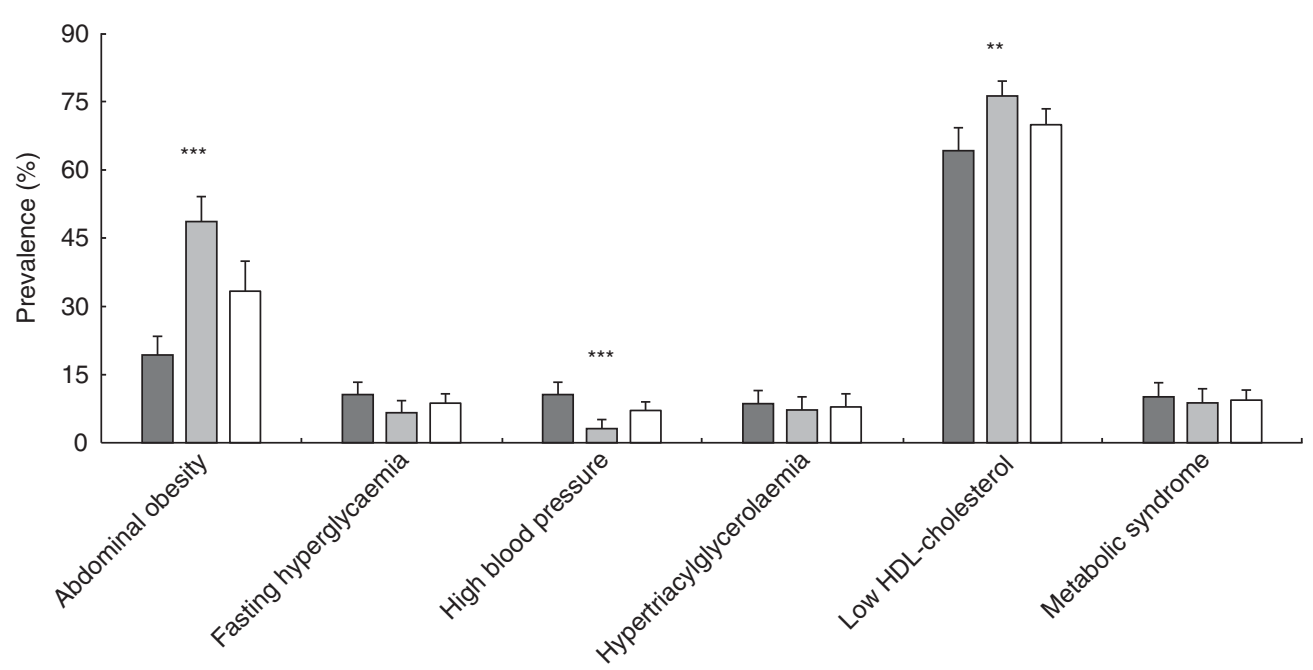

Fig. 1 Prevalence rates of cardiovascular risk factors and metabolic syndrome (with $95 \%$ confidence intervals represented by vertical bars) among adolescents ( $n$ 667) aged $16-17$ years ( $\square$, males; $\square$, females; $\square$, overall sample) from Santiago, Chile. Significant difference between males and females (Pearson's $\chi^{2}$ test): ${ }^{\star \star} P<0.01,{ }^{\star \star \star} P<0.001$

Table 2 Influence of biological, anthropometric and lifestyle factors (dependent variables) on the risk of metabolic syndrome (independent variable) in healthy male adolescents aged 16-17 years from Santiago, Chile ( $n$ 348)

\begin{tabular}{|c|c|c|c|c|c|c|c|c|}
\hline \multirow[b]{3}{*}{ Variable } & \multirow{2}{*}{\multicolumn{2}{|c|}{ Unadjusted OR }} & \multicolumn{6}{|c|}{ Adjusted OR } \\
\hline & & & \multicolumn{2}{|c|}{ Model 1} & \multicolumn{2}{|c|}{ Model 2} & \multicolumn{2}{|c|}{ Model 3} \\
\hline & OR & $95 \% \mathrm{Cl}$ & OR & $95 \% \mathrm{Cl}$ & OR & $95 \% \mathrm{Cl}$ & OR & $95 \% \mathrm{Cl}$ \\
\hline LGS inflammation & $2 \cdot 65^{\star \star}$ & $1 \cdot 26,5 \cdot 58$ & $3 \cdot 14^{* *}$ & $1 \cdot 34,7 \cdot 31$ & $1 \cdot 73$ & $0.63,4.78$ & 1.65 & $0.58,4.78$ \\
\hline Low adiponectin & $2 \cdot 65^{\star \star}$ & $1.28,5.45$ & 1.69 & $0.75,3.79$ & 1.53 & $0.56,4.15$ & 1.59 & $0.57,4.48$ \\
\hline Insulin resistance & $10 \cdot 26^{\star \star \star}$ & $4.83,21 \cdot 8$ & $10 \cdot 37^{\star \star \star}$ & $4 \cdot 66,23 \cdot 1$ & $3 \cdot 20^{*}$ & $1.20,8.54$ & $3.00^{*}$ & $1 \cdot 10,8 \cdot 23$ \\
\hline Obesity & $28 \cdot 29^{\star \star \star}$ & $12 \cdot 1,66 \cdot 1$ & - & - & $3.42^{*}$ & $1.23,9.51$ & $3 \cdot 74^{*}$ & $1 \cdot 23,10 \cdot 8$ \\
\hline Relative sarcopenia & $79 \cdot 13^{\star \star \star}$ & $18.4,339.8$ & - & - & $25 \cdot 9^{\star \star \star}$ & $5 \cdot 22,128 \cdot 9$ & $21 \cdot 2^{\star \star \star}$ & $4 \cdot 18,107.5$ \\
\hline Physical inactivity & $4.91^{\star \star \star}$ & $2 \cdot 38,10 \cdot 1$ & - & - & - & - & $2 \cdot 94^{*}$ & $1 \cdot 12,7 \cdot 72$ \\
\hline Unhealthy food intake & 0.82 & $0.34,1.96$ & - & - & - & - & - & - \\
\hline \multirow{3}{*}{$\begin{array}{l}\text { Likelihood ratio }\left(\chi^{2}\right) \\
\text { Hosmer-Lemeshow } \\
\text { Correctly classified }(\%)\end{array}$} & & & \multirow{3}{*}{\multicolumn{2}{|c|}{$\begin{array}{c}44.95^{\star \star \star} \\
6 \cdot 20(P=0 \cdot 19) \\
89.7\end{array}$}} & \multirow{3}{*}{\multicolumn{2}{|c|}{$\begin{array}{c}107 \cdot 1^{\star \star \star} \\
5 \cdot 34(P=0 \cdot 14) \\
91 \cdot 1\end{array}$}} & \multirow{3}{*}{\multicolumn{2}{|c|}{$\begin{array}{c}112 \cdot 0^{\star * *} \\
5.33(P=0.50) \\
92.5\end{array}$}} \\
\hline & & & & & & & & \\
\hline & & & & & & & & \\
\hline
\end{tabular}

LGS, low-grade systemic; -; non-observed; hs-CRP, high-sensitivity C-reactive protein; HOMA-IR; homeostatic model assessment-insulin resistance index. Model 1, biological variables; model 2, model 1 plus anthropometric variables; model 3, model 2 plus lifestyle factors.

LGS inflammation: hs-CRP $>75$ th percentile (hs-CRP $\geq 1.1 \mathrm{mg} / \mathrm{l}$ ). Low adiponectin: adiponectin $\leq 25$ th percentile (adiponectin $\leq 7.9 \mu \mathrm{g} / \mathrm{ml}$ ). Insulin resistance: HOMA-IR $\geq 2 \cdot 6$. Obesity: BMI $Z$-score $\geq 2$. Relative sarcopenia: $\%$ fat-free mass index $\leq 25$ th percentile. Physical inactivity: physical activity score $\leq 3$. Unhealthy food intake: food index score $\leq 3.3$.

Statistical significance: ${ }^{\star} P<0.05,{ }^{\star \star} P<0.01,{ }^{\star \star \star} P<0.001$. 
components of MetS and a higher risk of MetS, regardless of age and $\operatorname{sex}^{(36)}$. In males from our sample, obesity was independently associated with higher risk of MetS. In females, however, obesity lost its influence after accounting for IR. This could be due to an underestimation of total body fat and metabolic risk when obesity is diagnosed by BMI, or the influence might be mediated by $\mathrm{IR}^{(37,38)}$.

Relative sarcopenia showed a strong, direct and independent association with the risk of MetS in both sexes, which is consistent with results found in other contexts. In children and adolescents, higher levels of muscular fitness have been inversely associated with obesity, IR, clustered cardiometabolic risk and inflammation ${ }^{(39-41)}$. Likewise, muscular and cardiorespiratory fitness were independently associated with metabolic risk in European adolescents, according to the HELENA (Healthy Lifestyle in Europe by Nutrition in Adolescence) study ${ }^{(42)}$. It is well known that physical inactivity increases the risk of several adverse health conditions, including major noncommunicable diseases such as CHD, type 2 diabetes, and breast and colon cancers, not to mention reductions of life expectancy ${ }^{(43)}$. However, in our sample, physical inactivity was independently associated with MetS only in males. Several studies suggest that because males and females have different levels of physical activity, and the variables associated with activity levels are not consistent across the sexes, there could be differences in the impact of physical inactivity on metabolic risk ${ }^{(44,45)}$. In the present study, physical activity was assessed by self-report of the time allocated to repetitive, planned physical activity during the week, regardless of the intensity or type of exercise. This may have led to underestimation of the impact of physical inactivity on metabolic risk in females.

\section{Limitations and strengths}

The current research has some weaknesses that should be considered. Our sample is not representative of the Chilean adolescent population, as it was made up of adolescents from low to middle SES living in urban Santiago. Participants were drawn from a longitudinal cohort that began in infancy as a preventive trial of Fe-deficiency anaemia. The inclusion criteria mandated that all participants weigh $\geq 3 \mathrm{~kg}$ and be born full-term to healthy mothers. Thus, our results cannot be generalized to a larger population. However, our findings may be equally relevant for a number of reasons. According to the Chilean National Health Survey, the prevalence of obesity, type 2 diabetes and CVD is significantly higher among individuals from low to middle SES ${ }^{(15)}$. On the other hand, low- to middle-SES Chilean adolescents are highly exposed to risk factors that have a direct effect on the development of non-communicable diseases, including physical inactivity and processed foods full of fat and sugar ${ }^{(26,46,47)}$. A further limitation is the cross-sectional nature of the study, which limits the ability to draw conclusions related to the temporality of these relationships. Future studies should aim to longitudinally explore links between biological and environmental factors and MetS, which may become clearer over time. Finally, physical activity was not assessed with an objective measurement ${ }^{(48)}$. However, we used a questionnaire that was validated using accelerometrybased activity monitors in a sample of adolescents from urban Santiago and from all SES groups ${ }^{(27)}$. Muscle mass was assessed using dual-energy X-ray absorptiometry rather than whole-body MRI ${ }^{(49)}$. Nevertheless, dual-energy X-ray absorptiometry methodology and fat-free mass index have better sensitivity than BMI for estimating the ratio between muscle and fat tissue ${ }^{(22,50)}$.

In spite of these limitations, the research provides results that confirm an increased cardiovascular and metabolic risk in a sample of adolescents who grew up during a rapid nutritional and epidemiological transition. These results may be useful for middle-income countries and populations going through similarly rapid nutritional and epidemiological transitions, including several countries in Latin America, Eastern Europe and South-East Asia, and immigrants and ethnic minorities in the USA and Western Europe ${ }^{(51,52)}$. A further important contribution is the confirmation that reduced muscle development might be considered a relevant risk factor preceding noncommunicable diseases and as important as obesity and IR. A major public health challenge will be to increase the number of years free of disability in a generation exposed to such dramatic changes in the food and physical activity environment ${ }^{(53)}$. Public policies and programmes at the school level that promote active lifestyles in children and adolescents, and regulate the sale of energy-dense foods, are sorely needed. Promotion of patterns lifestyle that include higher dairy consumption along with more adequate breakfast, high-fibre foods, more frequent meals and higher physical activity among children, adolescents and their families should be considered as one of the components of any obesity prevention initiative ${ }^{(54)}$.

\section{Acknowledgements}

Acknowledgements: The authors are indebted to Dr Betsy Lozoff from the Center for Human Growth and Development \& School of Medicine, University of Michigan, who conceived and developed this cohort when they were infants to study the effects of preventing Fe-deficiency anemia. Dr Lozoff led studies that maintained the cohort throughout childhood and into adolescence. Financial support: This research was carried out with financial support from the National Heart, Lung, and Blood Institute, National Institutes of Health (grant number R01HL088530-2980925). P.C.-B. was supported by the Advanced Human Capital Program (grant code 79140003) from the National Council for Scientific Research and Technology (CONICYT) (Chile). The funders had no role in the design, analysis or writing of this article. Conflict of interest: None. Authorship: R.B. conceived the 
study, collected data and literature, analysed data and wrote the manuscript; P.C. analysed data and wrote and edited the manuscript; M.R. collected data; S.G. conceived the study; E.B. provided expertise related to the cohort study, epidemiological approaches and language assistance; C.A. assisted in data interpretation. All authors had final approval of the submitted and published versions. Ethics of human subjects participation: The study was approved by the institutional review boards of the University of Michigan, Institute of Nutrition and Food Technology at the University of Chile, and the University of California, San Diego. Parents or primary caregivers of the participants provided informed consent and participants assented to participation.

\section{References}

1. Van Vliet M, Heymans MW, Von Rosenstiel IA et al. (2011) Cardiometabolic risk variables in overweight and obese children: a worldwide comparison. Cardiovasc Diabetol 10, 106.

2. Attard SM, Herring AH, Howard AG et al. (2013) Longitudinal trajectories of BMI and cardiovascular disease risk: the national longitudinal study of adolescent health. Obesity (Silver Spring) 21, 2180-2188.

3. Mattsson N, Rönnemaa T, Juonala M et al. (2008) Childhood predictors of the metabolic syndrome in adulthood. The Cardiovascular Risk in Young Finns Study. Ann Med 40, 542-552.

4. Morrison JA, Fredman LA, Wang P et al. (2008) Metabolic syndrome in childhood predicts adult metabolic syndrome and type- 2 diabetes mellitus 20 to 30 years later. J Pediatr 152, 201-206.

5. Walter S, Kunst A, Mackenbach J et al. (2009) Mortality and disability: the effect of overweight and obesity. Int J Obes (Lond) 33, 1410-1418.

6. Lightwood J, Bibbins-Domingo K, Coxson P et al. (2009) Forecasting the future economic burden of current adolescent overweight: an estimate of the coronary heart disease policy model. Am J Public Health 99, 2230-2237.

7. Chiarelli F \& Marcovecchio ML (2008) Insulin resistance and obesity in childhood. Eur J Endocrinol 159, Suppl. 1, S67-S74.

8. Friend A, Craig L \& Turner S (2013) The prevalence of metabolic syndrome in children: a systematic review of the literature. Met Syndr Related Disord 11, 71-80.

9. Shaibi QG \& Goran IM (2008) Examining metabolic syndrome definitions in overweight Hispanic youth: a focus on insulin resistance. J Pediatr 152, 171-176.

10. Reyes M, Gahagan S, Díaz E et al. (2011) Relationship of adiposity and insulin resistance mediated by inflammation in a group of overweight and obese Chilean adolescents. Nutr J 10, 4-7.

11. Steene-Johannessen J, Anderssen SA, Kolle E et al. (2009) Low muscle fitness is associated with metabolic risk in youth. Med Sci Sports Exerc 41, 1361-1367.

12. Cecchini M, Sassi F, Lauer JA et al. (2010) Tackling of unhealthy diets, physical inactivity, and obesity: health effects and cost-effectiveness. Lancet 376, 1775-1184.

13. Albala C, Vio F, Kain J et al. (2002) Nutrition transition in Chile: determinants and consequences. Public Health Nutr 5, 123-128

14. Vio F, Albala C \& Kain J (2008) Nutrition transition in Chile revisited: mid-term evaluation of obesity goals for the period 2000-2010. Public Health Nutr 11, 405-412.

15. Ministry of Health (2011) National Health Survey 2009-2010. Santiago: Ministry of Health.
16. Muzzo S, Cordero J, Burrows R et al. (2004) Trend in nutritional status and stature among school age children in Chile. Nutrition 20, 867-973.

17. Burrows R, Weisstaub G, Ceballos Z et al. (2007) Metabolic syndrome in children and adolescents: association with insulin sensitivity, degree and distribution of overweight. Rev Med Chil 135, 174-181.

18. Burrows R, Leiva L, Wiesstaub G et al. (2011) High HOMA-IR, adjusted for puberty, relates to the metabolic syndrome in overweight and obese Chilean youths. Pediatr Diabetes 12, 212-218.

19. Mardones F, Arnaiz P, Barja S et al. (2013) Nutritional status, metabolic syndrome and insulin resistance in children from Santiago (Chile). Nutr Hosp 28, 1999-2005.

20. Ministry of Education (2011) Informe de Resultados Nacionales de Educación Física 2011. Santiago: Ministry of Education.

21. Lozoff B, De Andraca I, Castillo M et al. (2003) Behavioral and developmental effects of preventing iron-deficiency anemia in healthy full-term infants. Pediatrics 112, 846-854.

22. Wells JCK \& Fewtrell MS (2006) Measuring body composition. Arch Dis Child 91, 612-617.

23. Burrows R, Correa-Burrows P, Reyes M et al. (2015) Healthy Chilean adolescents with HOMA-IR $\geq 2.6$ have increased cardiometabolic risk: association with genetic, biological, and environmental factors. J Diabetes Res article ID 783296.

24. Zimmet P, Alberti KG, George MM et al. (2007) The metabolic syndrome in children and adolescents - an IDF consensus report. Pediatr Diabetes 8, 299-306.

25. Alberti KG, George MM, Eckel RH et al. (2009) Harmonizing the metabolic syndrome: a joint interim statement of the International Diabetes Federation Task Force on Epidemiology and Prevention; National Heart, Lung, and Blood Institute; American Heart Association; World Heart Federation; International Atherosclerosis Society; and International Association for the Study of Obesity. Circulation 120, $1640-1645$.

26. Burrows R, Díaz E, Sciaraffia V et al. (2008) Dietary intake and physical activity in school age children. Rev Med Chile 136, 53-63.

27. Godard C, Rodríguez MP, Lera L et al. (2008) Value of a clinical test for assessing physical activity in children. Rev Med Chil 136, 1155-1162.

28. Ministry of Health (2013) Global School-Based Survey. Santiago: Department of Epidemiology, Ministry of Health.

29. Ministry of Health (2014) National Food Consumption Survey. Santiago: Ministry of Health.

30. Bustos P, Da Silva AA, Amigo H et al. (2007) Metabolic syndrome in young adults from two socioeconomic Latin American settings. Nutr Metab Cardiovasc Dis 17, 581-589.

31. Pirkola J, Tammelin T, Bloigu A et al. (2008) Prevalence of metabolic syndrome at age 16 using the International Diabetes Federation paediatric definition. Arch Dis Child $\mathbf{9 3}$, 945-951.

32. Park SH, Park JH, Kang JW et al. (2013) Prevalence of the metabolic syndrome and abnormal lipids levels among Korean adolescents. J Pediatr Child Health 49 , 582-587.

33. United Nations Development Programme (2014) Human Development Report 2014. Sustaining Human Progress: Reducing Vulnerabilities and Building Resilience. New York: UNDP.

34. Stienstra R, Van Diepen JA, Tack CJ et al. (2011) Inflammasome is a central player in the induction of obesity and insulin resistance. Proc Natl Acad Sci U S A 108, 15324-15329.

35. Kadowaki T, Yamauchi T, Kubota N et al. (2006) Adiponectin and adiponectin receptors in insulin resistance, diabetes, and the metabolic syndrome. J Clin Invest 116, 1784-1792. 
36. Juárez-López C, Klünder-Klünder M, Medina-Bravo P et al. (2010) Insulin resistance and its association with the components of the metabolic syndrome among obese children and adolescents. BMC Public Health 10, 318.

37. Shah NR \& Braverman ER (2012) Measuring adiposity in patients: the utility of body mass index (BMI), percent body fat, and leptin. PLoS One 7, e33308.

38. Shea JL, King MTC, Yi Y et al. (2012) Body fat percentage is associated with cardiometabolic dysregulation in BMIdefined normal weight subjects. Nutr Metab Cardiovasc Dis 22, 741-747.

39. Benson AC, Torode ME \& Singh MA (2006) Muscular strength and cardiorespiratory fitness is associated with higher insulin sensitivity in children and adolescents. Int $J$ Pediatr Obes 1, 222-231.

40. Jurca R, Lamonte MJ, Church TS et al. (2004) Associations of muscle strength and fitness with metabolic syndrome in men. Med Sci Sports Exerc 36, 1301-1307.

41. Ortega FB, Ruiz JR, Castillo MJ et al. (2008) Physical fitness in childhood and adolescence: a powerful marker of health. Int J Obes (Lond) 32, 1-11.

42. Artero EG, Ruiz JR, Ortega FB et al. (2011) Muscular and cardiorespiratory fitness are independently associated with metabolic risk in adolescents: the HELENA study. Pediatr Diabetes 12, 704-771.

43. Lee IM, Shiroma EJ, Lobelo F et al. (2012) Effect of physical inactivity on major non-communicable diseases worldwide: an analysis of burden of disease and life expectancy. Lancet 380, 219-229.

44. Azevedo MR, Pavin Araújo CL, Fossati Reichert F et al. (2007) Gender differences in leisure-time physical activity. Int J Public Health 52, 8-15.
45. Van Mechelen W, Twisk JWR, Bertheke Post G et al. (2000) Physical activity of young people: the Amsterdam Longitudinal Growth and Health Study. Med Sci Sports Exerc 32, 1610-1616.

46. Correa-Burrows P \& Burrows R (2011) Inactive lifestyles and obesity in Chilean youth: individual costs in health-related choices. Health Educ J 73, 657-667.

47. Coeval A, Molina A, Root A et al. (2008) Trends in obesity and diabetes prevalence in a Chilean urban population. Metab Syndr Relat Disord 6, 219-222.

48. Trost SG, McIver KL \& Pate RR (2005) Conducting accelerometer-based activity assessment in field-based research. Med Sci Sports Exerc 37, 11 Suppl, S531-S543.

49. Lee S \& Kuk JL (2013) Changes in fat and skeletal muscle with exercise training in obese adolescents: comparison of whole-body MRI and dual energy X-ray absorptiometry. Obesity (Silver Spring) 21, 2063-2071.

50. Lee Kelly LT, Wilson EK \& Heymsfield BS (2009) Dual energy X-ray absorptiometry body composition reference values from NHANES. PLoS One 4, e7038.

51. Amuna P \& Zotor FB (2008) Epidemiological and nutrition transition in developing countries: impact on human health and development. Proc Nutr Soc 67, 82-90.

52. Dijkshoorn $\mathrm{H}$, Nicolaou $\mathrm{M}$, Ujcic-Voortma JK et al. (2014) Overweight and obesity in young Turkish, Moroccan and Surinamese migrants of the second generation in the Netherlands. Public Health Nutr 17, 2037-2044.

53. Walls H, Backholer K, Proietto J et al. (2012) Obesity and trends in life expectancy. J Obes 2012, 107989.

54. Moschonis G, Kalliora AC, Costarelli V et al. (2014) Identification of lifestyle patterns associated with obesity and fat mass in children: the Healthy Growth Study. Public Health Nutr 17, 614-624. 